\title{
Os significados do TDAH em discursos de docentes dos anos iniciais
}

Simone Patrícia da Silva* , Carina Pessoa Santos** , Pedro de Oliveira Filho** * http://dx.doi.org/10.1590/0103-7307201507708

\section{Resumo}

Trata-se de uma pesquisa cujo objetivo é investigar os significados do TDAH (Transtorno do Déficit de Atenção com Hiperatividade) em discursos de docentes do ensino fundamental, das redes pública e privada, em Pernambuco. Foram realizadas vinte entrevistas, submetidas à técnica de análise da Psicologia Social Discursiva, cujo foco de interesse é a linguagem em ação, a função, os efeitos e o caráter argumentativo do discurso. A partir dos dados analisados, os autores mostram que os alunos considerados portadores do TDAH ou aqueles que apresentam atividade acima da média são colocados em categorias que apresentam um viés psicologizante ou biologizante. Os autores observam ainda que os comportamentos tidos como desviantes são explicados por categorias que contrastam estados de anormalidade e de normalidade. Ao individualizarem * Universidade Federal de Pernambuco (UFPE Psicologia), Recife, PE, Brasil. simonecatia@hotmail.com

** Universidade Federal de Pernambuco (UFPE Psicologia), Recife, PE, Brasil. cpspostal@yahoo.com.br

*** Universidade Federal de Campina Grande (UFCG - Psicologia), Campina Grande, PB, Brasil. deoliveirafilhopedro@gmail. com

os casos dos alunos, os professores também evitam elaborar explicações sobre o modelo escolar. 0 estudo remete às dificuldades da inserção e inclusão no espaço educacional.

Palavras-chave: TDAH, discurso, comportamento desviante, educação, psicologia social 


\title{
Meanings of ADHD in the discourse of elementary school teachers
}

\begin{abstract}
This article discusses the meanings of $A D H D$ in the discourse of Pernambuco public and private elementary school teachers. Twenty interviews were carried out and submitted to Discursive Social Psychology analysis, which focuses on the speech in action, its function, effects and argumentative characteristic. The analysis shows that students considered as having ADHD are those perceived as presenting higher levels of physical activity. They are, in turn, classified in psychological or biological categories. Behaviors seen as deviant are explained in terms of contrast between abnormality and normality, and the children's perceived problems are individualized and extracted from the school context. These results thus highlight the barriers to educational inclusion.
\end{abstract}

Keywords: $A D H D$, discourse, deviant behavior, education, social psychology 


\section{Introdução}

Neste trabalho, busca-se analisar, em discursos de docentes, os significados produzidos sobre o Transtorno de Déficit de Atenção/Hiperatividade (TDAH), quando este é utilizado para explicar as relações e os comportamentos dos alunos no ambiente escolar. 0 interesse pelo tema decorreu da percepção do uso crescente desse termo no espaço educacional, para explicar dificuldades de aprendizagem e comportamentais dos discentes. Como destacam Legnani e Almeida (2008), atualmente, esse diagnóstico tem sido uma das descrições médicas mais utilizadas para dar vazão à psicopatologização de dificuldades que comparecem na infância, partindo-se de uma concepção que reduz o desenvolvimento e o psiquismo humanos a explicações biológicas. Dessa forma, cabe questionar a maneira como termos médicos vêm sendo apropriados nos discursos de profissionais que lidam diretamente com o desenvolvimento infantil e a educação.

Em se tratando do âmbito escolar, discentes cujo comportamento destoa do esperado pelo ambiente educacional, em geral, são classificados por discursos que tendem a construir estereótipos a seu respeito. Nesse sentido, não é raro encontrar, nas falas de profissionais da educação, termos, narrativas e descrições que focalizam as características individuais dos sujeitos, responsabilizando-os pelas dificuldades de aprendizagem e por problemas comportamentais (Landskron \& Sperb, 2008). Tais produções discursivas são antigas, como mostram as pesquisas desenvolvidas na década de 1990 por Collares e Moisés (1996) e Patto (2002), nas quais fica claro que os alunos com características biopsicossociais indesejáveis podem ser facilmente categorizados no ambiente escolar como inaptos, incapazes, problemáticos ou, em alguns casos, portadores de algum tipo de déficit ou distúrbio limitador da aprendizagem e do ajuste à escola.

Nos referidos estudos, é possível encontrar exemplos nos quais há uma tendência em ressaltar como responsável pelas dificuldades escolares aquilo que é estranho, dicotômico e fora dos padrões preestabelecidos. Segundo Foucault (2001), na obra Os anormais, os sujeitos são colocados em categorias que determinam seus traços individuais como responsáveis pelos comportamentos desviantes e estranhos. No caso do TDAH não é diferente, pois no âmbito escolar constroem-se categorias discursivas que tendem a ressaltar os traços individuais dos sujeitos como causadores dos seus problemas educacionais. Dessa forma, tenta-se explicar aquilo que ocorre na escola por termos e descrições que acabam por reforçar a patologização desse 
espaço. Silva (2010) ressalta que problemas antes considerados de ordem disciplinar e passíveis de intervenção no próprio âmbito escolar hoje são tratados por meio de prontuários dos discentes, produzindo um “viés médico" nesse espaço (p.169).

Partindo da discussão acima, empreendemos um estudo com docentes, no qual procuramos compreender a natureza do fenômeno em nosso contexto. A pesquisa encontra-se norteada por algumas questões: Que repertórios interpretativos são utilizados para nomear e descrever o TDAH? Quais argumentos e teorias são mobilizados para explicar os distúrbios? Como os docentes definem e descrevem o aluno portador do distúrbio?

\section{Controvérsias sobre o TDAH}

Segundo Legnani e Almeida (2008), as primeiras descrições médicas sobre 0 TDAH apareceram no início do século XX, mas foi a partir da década de 1970 que elas começaram a ganhar visibilidade no diagnóstico de crianças e adolescentes em processo de escolarização, principalmente no contexto norte-americano. Nos anos de 1940 utilizava-se a terminologia “Lesão Cerebral Mínima” (LCM) que, na década de 1960, foi substituída por “Disfunção Cerebral Mínima” (DCM), devido à ausência de comprovações empíricas para a existência de lesões no aparato cerebral. Dentre os discursos que relacionam os problemas escolares do aluno a algum tipo de transtorno, ganharam força, a partir da década de 1990, aqueles nos quais eram ressaltados os sintomas do TDAH, usados com frequência no cenário escolar contemporâneo para justificar o mau desempenho do discente. Segundo Benczick (2002), o distúrbio tornou-se o "rótulo" para a maioria dos alunos que apresentam algum tipo de conduta desviante. Esse fato levou problemas de ordem educacional ou psicológica a serem nomeados enganosamente de hiperatividade.

No DSM IV (APA, 2002), o TDAH é caracterizado por cinco critérios gerais: a) padrão persistente de desatenção e/ou hiperatividade, mais frequente ou severo do que aquele encontrado em indivíduos com níveis equivalentes de desenvolvimento; b) presença de sintomas hiperativo-impulsivos que causam prejuízos e devem estar presentes antes dos 7 anos de idade; c) presença, em pelo menos dois contextos como casa, escola ou trabalho - de algum prejuízo devido a esses sintomas; d) claras evidências de interferência no funcionamento social, acadêmico ou ocupacional em termos evolutivos; e) ocorrência não exclusiva dessa perturbação durante o curso de Transtorno Invasivo do Desenvolvimento, Esquizofrenia ou outro Transtorno Psicótico 
e ausência de outro transtorno mental que melhor a explique. Embora a maioria dos indivíduos apresente tanto sintomas de desatenção quanto de hiperatividade-impulsividade, em alguns casos, há predominância de um ou outro padrão, levando a subtipos do transtorno, que devem ser diagnosticados a partir do padrão predominante de sintomas dos últimos seis meses.

Assim, observa-se o TDAH de tipo combinado, caracterizado por seis (ou mais) sintomas de desatenção e seis (ou mais) sintomas de hiperatividade-impulsividade que persistem por pelo menos seis meses, sendo maioria nos diagnósticos de crianças e adolescentes; predominantemente desatento, quando seis (ou mais) sintomas de desatenção e menos de seis sintomas de hiperatividade-impulsividade persistem por pelo menos seis meses; e o subtipo predominantemente hiperativo-impulsivo, em que seis (ou mais) sintomas de hiperatividade-impulsividade e menos de seis sintomas de desatenção persistem por pelo menos seis meses.

Longe de ser consensual, esse transtorno vem acompanhado de muita polêmica e incertezas, principalmente devido ao número crescente de crianças e adolescentes que passaram a ser detectados como portadores do distúrbio em vários países e em razão da prescrição de estimulantes no seu tratamento (Caliman, 2009). Legnani e Almeida (2008) destacam que o uso indiscriminado de medicamentos na infância, com o objetivo de normatização de comportamentos e supressão de sintomas, tem como agravante o fato de que a criança pode vir a desenvolver, por meio do aprendizado, a crença de que a ingestão de pílulas pode eliminar qualquer tipo de mal-estar, conduzindo a um apaziguamento ilusório da angústia, dos problemas e dificuldades.

Apesar da grande quantidade de diagnósticos, estima-se que sua prevalência seja de 3 a 6\% da população infantil geral (APA, 2002; Rhode \& Halpern, 2004). Segundo Gomes et al. (2007), seu diagnóstico é clínico, realizado com base na manifestação dos sintomas apresentados pelo indivíduo, em sua história e nas informações prestadas por pais e professores. A partir desses dados, o profissional faz o diagnóstico final e prescreve o tratamento, que pode incluir intervenção terapêutica e medicamentosa. Graeff e Vaz (2008) acrescentam que, de acordo com as técnicas definidas para avaliação, os resultados diagnósticos tendem a apresentar diferenças consideráveis, de maneira que, quanto mais completa e criteriosa for a avaliação, menor a possibilidade de equívocos e maiores os recursos disponíveis para o planejamento de uma intervenção adequada. Logo, o uso de escalas, testes psicológicos e neuropsicológicos pode ser de muita importância para esse processo. 
No contexto da escola, o uso do termo TDAH para explicar as dificuldades do aluno suscita inúmeros questionamentos. Segundo Benedetti e Cunha (2008), a escola vem encaminhando um grande número de sujeitos para tratamento clínico, o que evidencia a centralização dos problemas em aspectos individuais, além de mostrar a dissociação entre esse sujeito e o contexto social mais amplo no qual está inserido. Ademais, alertam as autoras, é necessário problematizar esses encaminhamentos, uma vez que podem estar sendo utilizados para isentar a escola e seus profissionais da sua responsabilidade.

Dessa forma, procura-se refletir, neste estudo, sobre tais problemáticas. A pesquisa encontra-se ancorada na abordagem teórica da Psicologia Social Discursiva, cujo foco de análise se concentra na natureza argumentativa do discurso, em sua função, construção e variabilidade (Billig, 2008; Oliveira Filho, 2011; Potter \& Wetherell, 1987; Wetherell \& Potter, 1992). Defende-se, com base em Van Dijk (2004), que, ao orientar a fala para posicionar um indivíduo numa determinada categoria ou para produzir e defender um argumento, constrói-se uma versão de fatos, na qual está presente a maneira como se conceitua, compreende e vive o cotidiano. Assim, quando se analisam as produções discursivas dos indivíduos, torna-se possível apreender a forma como identidades são produzidas e como estereótipos negativos contra grupos considerados diferentes são disseminados.

Nessa perspectiva teórica, o posicionamento é compreendido no contexto das práticas discursivas. Dessa forma, o foco de análise está na maneira como os sujeitos se posicionam e apresentam os outros indivíduos nas suas conversações, narrativas, relatos e histórias; ou quando expressam suas opiniões em um debate sobre assuntos controversos (Potter, 1998; Wetherell, 1998; Wetherell \& Potter, 1992). Esses autores destacam que, numa ação discursiva, são produzidas versões, consistentes ou inconsistentes, de pessoas, de estados mentais e emocionais, de suas identidades e dos demais indivíduos. Logo, para identificar os sentidos de uma questão, é importante perceber como os sujeitos elaboram distintas posições nas suas práticas (Spink \& Medrado, 2000).

\section{Método}

\section{Participantes}

Foram entrevistadas 20 professoras do Ensino Fundamental, sendo 14 da rede pública e 6 da rede privada, em 2 municípios pernambucanos. Suas idades variaram de 22 a 52 anos; a média de idade é 36, 6 e o tempo de exercício docente, entre 1 e 20 
anos. A área de formação predominante é ciências humanas. Todas elas são identificadas no interior do texto por pseudônimos. Os critérios de inclusão adotados foram o exercício mínimo de um ano de docência no Ensino Fundamental e o interesse em participar da pesquisa.

\section{Instrumento e procedimentos de geração de dados}

Os dados foram coletados com o uso de entrevista semiestruturada, cujo roteiro se baseou nos objetivos da investigação. 0 critério utilizado para determinar a quantidade de participantes foi o ponto de saturação, que permitiu detectar que informações novas não estavam mais aparecendo no discurso dos sujeitos (Lang, Campos \& Demartini, 2001). As entrevistas foram realizadas individualmente, gravadas, transcritas na íntegra e depois analisadas. Todas elas aconteceram no próprio local de trabalho dos participantes.

\section{Análise dos dados}

A análise do material discursivo foi norteada pela Psicologia Social Discursiva, perspectiva teórico-metodológica que vem desenvolvendo um método de análise de discurso que focaliza o aspecto argumentativo, a construção e os efeitos do discurso (Billig, 2008; Potter \& Wetherell, 1987; Wetherell \& Potter, 1992).

Depois da transcrição, realizou-se a codificação que, na perspectiva adotada, não é a análise propriamente dita, mas a preparação para um estudo minucioso do material colhido, facilitando a análise (Potter \& Wetherell, 1987).

Os referidos autores salientam que a análise procura evidenciar as categorias psicológicas mobilizadas no discurso, a forma como são construídas as relações sociais. E, além disso, busca identificar a maneira como os argumentos são organizados retoricamente para defender ou combater uma versão de mundo ou de realidade.

Nesse tipo de estudo, entende-se que o significado de uma palavra ou expressão está relacionado ao contexto de sua produção, ao uso que se faz dos termos nas interações. Dessa forma, procura-se observar a entonação das palavras, a sequência de sua construção, as pausas, a forma como o discurso é organizado em resposta ao discurso que o precede, pois se entende que tais aspectos possibilitam uma interpretação dos recursos utilizados pelos sujeitos na construção de fatos (Edwards, 2006). Nesse sentido, foram preservadas, nas transcrições das entrevistas, as pausas, a linguagem informal do cotidiano e os usos da linguagem que transgridem a norma culta. 
Foram organizados em categorias os temas que surgiram nos discursos dos participantes da pesquisa. Ressalta-se que as categorias, na análise discursiva, são abrangentes, de maneira a incluir “todas as instâncias limítrofes" (Gill, 2002, p. 254). Nesse caso, à medida que a análise se torna mais sofisticada, talvez se tenham de inserir novas categorias. No processo preliminar de estudo, elas teriam a função de organizar os dados colhidos (Potter \& Wetherell, 1987).

\section{Resultados e discussão \\ Os significados do TDAH em discursos de discentes}

Quando as participantes foram questionadas sobre o significado do termo TDAH, observou-se, em suas falas, que não havia uma única definição para o transtorno, mas explicações que revelavam a variabilidade discursiva sobre o assunto. Dessa forma, encontram-se, nos repertórios usados pelos sujeitos, termos do discurso científico e do conhecimento do senso comum. Além de um conjunto de termos que reforçam a ideia de normalidade. As falas seguintes são representativas do discurso científico.

Transtorno geralmente é uma doença... né? E é confundida muitas vezes. Porque às vezes o menino é hiperativo no comportamento, mas isso não quer dizer que ele tenha algum problema realmente neurológico... né? (Carla).

Olha, é um distúrbio de comportamento e o principal desafio é identificar as causas (Janete).

As professoras Carla e Janete utilizam termos da literatura científica para definir o TDAH: “neurológico”, “doença”, “distúrbio de comportamento”. A função desse recurso é atribuir crédito às suas falas, pois não trazem impressões do senso comum, mas são termos, em geral, usados no campo especializado (Potter, 1998). Na primeira definição, o sentido é associado ao campo da psiquiatria. Assim, Carla constrói cuidadosamente um discurso no qual procura distinguir o sentido do termo "hiperatividade", quando usado comumente para indicar um comportamento infantil considerado normal, e o significado dessa expressão, quando empregada para falar de problemas neurológicos. A mesma referência a expressões especializadas é encontrada na fala de Janete. Além disso, ela constrói o discurso a fim de mostrar que existe controvérsia sobre as causas do distúrbio (Benedetti \& Cunha, 2008). Também encontramos depoimentos nos quais se 
parte de uma concepção de normalidade como parâmetro para definir o transtorno da ausência ou do excesso de algo. Um exemplo são estas falas:

Bom para mim, quando fala em hiperatividade... eu coloco como... uma criança especial, ela tem atitudes avassaladoras. A atitude delas é bem mais diferente do que de um aluno no seu ritmo normal de estudo (Gilsa).

Eu acredito que seja uma deficiência que a criança deve ter... e ai precisa de um apoio, não é? (Fiona).

É... como é que eu posso dizer... esse acúmulo de energia que é um critério a mais pra gente avaliar (Marilia).

Hiperatividade... eu acho que é aquela criança que ela tem uma certa... é um tipo voluntariedade, o tempo pra ela parece que não existe, ela faz as coisas com muita pressa, ela tem muita... energia, não é? (Raquel).

A professora Gilsa descreve a hiperatividade a partir de um relato no qual são maximizadas as ações da criança por meio da expressão "atitudes avassaladoras", que nesse contexto tem o sentido de produzir a anormalidade em relação a um padrão de conduta esperado no ambiente escolar. Tal fato fica mais claro quando a docente descreve essa criança como alguém cuja ação é "diferente” de uma criança que apresenta um "ritmo normal". Nesse caso, o mórbido, o doentio e o patológico recebe tal sentido a partir daquilo que é referenciado como normal (Canguilhem, 1995). O relato constrói o que é estranho, foge às regras e aos padrões preestabelecidos, como uma característica individual do sujeito (Foucault, 2001). O discurso de Fiona também é produzido para trazer essa ideia. Dessa forma, quando usa a palavra "deficiência", ela está associando a hiperatividade à ideia de algo fora do lugar, a algum tipo de disfunção.

No discurso feito por Marília, o estado de anormalidade referente ao distúrbio é produzido por uma descrição na qual é enfatizada a ideia de excesso: "acúmulo de energia”. Esse aspecto também é enfocado pela professora Raquel, que, em sua descrição, relaciona a hiperatividade ao desejo e à vontade do sujeito, quando ressalta sua "voluntariedade". 
Alguns docentes, assim como Raquel, procuram definir o transtorno a partir de características que entendem como próprias do aluno portador do transtorno. Observam-se, nesses relatos, algumas controvérsias e ambiguidades em relação ao assunto.

Dificuldade de aprendizagem é... comportamento, atitude, problema, não é? (Márcia).

Algum aluno que não desenvolve um comportamento bom na sala de aula... ele... ele é um bom aluno, mas ele se comporta assim (Leandra).

Pronto, eu acredito que é uma criança assim... inquieta, que não... se concentra nas tarefas, que não passa muito tempo fazendo a mesma coisa (Paulina).

Ah... desses alunos que não prestam a atenção, não conseguem parar quietos... não aprendem, não faz atividade... pra mim está nessa hiperatividade aí (Nelma).

Na fala de Márcia, o distúrbio é descrito de forma ambígua e a partir de alguns efeitos que causam problemas no ambiente escolar. A ênfase em relação ao comportamento também é encontrada na descrição de Leandra, que procura elaborar um relato no qual as ações do indivíduo aparecem de forma contrastante. Assim, esse sujeito é, ao mesmo tempo, apresentado como “bom aluno" e também descrito como alguém que não apresenta uma boa conduta.

Quando a professora Paulina inicia seu relato pela expressão “eu acredito”, ela deixa claro que sua opinião está baseada em suas próprias crenças ou em algum conhecimento do senso comum sobre o assunto. A partir daí, ela produz um relato em que o TDAH é categorizado de forma negativa. Nota-se que o parâmetro definidor do transtorno aparece, na fala da docente e na maioria dos outros discursos, sempre associado à ideia de desvio de um padrão de comportamento.

Isso fica evidente na fala da professora Nelma, que descreve as crianças com TDAH como aquelas que transgridem um determinado padrão de conduta: "não prestam a atenção", "não conseguem parar quietos", "não aprendem”, "não faz atividade”. A hiperatividade aqui tem claramente o sentido negativo de comportamento inadequado, incapacidade e limitação, já que concentração, silêncio, disciplina, realização de exercícios e obediência são tradicionalmente considerados imprescindíveis no con- 
texto escolar, para a aprendizagem do aluno e para o bom funcionamento da dinâmica escolar (Aquino, 2001, 1998).

O foco em aspectos de conduta revela a preocupação dos educadores com a disciplina, o silêncio, a imobilidade e a submissão no ambiente escolar. Talvez por isso, o aluno que apresenta uma conduta mais ativa que a média seja identificado, pela maioria dos professores, como portador do TDAH, pois ele rompe as normas estabelecidas e perturba a ordem escolar. Nesse caso, o distúrbio recebe o sentido de desvio social, sendo evidenciado a partir dos danos ou dos conflitos produzidos na dinâmica escolar. Isso fica mais claro quando os professores são solicitados a descrever os alunos com TDAH.

\section{Categorizando o aluno com TDAH}

Solicitou-se aos docentes que descrevessem o aluno considerado portador do TDAH. A maioria deles descreveu o discente a partir de características comportamentais, que ora enfocam o excesso de atividade, ora centralizam a desatenção. Os discursos a seguir são representativos da ação excessiva.

É aquela criança que numa palavra bem simples ela "perturba" [destaque da entrevistada], perturba demais, porque, como ela não consegue ficar numa cadeirinha... Nesse sistema numa cadeirinha olhando a professora, não ele não consegue. Então ela mexe no livro, ela puxa, ela amassa o papel do colega, ela conversa o tempo inteiro... é... assim... o andamento da turma, se não tiver cuidado, prejudica por conta dela (Maria).

Como já falei anteriormente, no caso da hiperatividade é uma criança assim... que procura chamar mais a atenção, que tá sempre... não para quieto em nenhum momento, conversa muito, assim... mexe com os outros colegas na sala de aula... é uma criança que não fica quieta (Tirza).

Olhe, ele não parava muito, falava muito, concentração ele não... ficava muito assim concentrado em uma atividade. Ele sempre estava mexendo com um, mexendo com outro (Marta).

Os discursos supracitados fazem referência às características individuais que a maioria das professoras entrevistadas entende como típicas das crianças com TDAH. Na descrição da professora Maria, é possível observar o uso de recursos que, retori- 
camente, têm a função de mostrar a conduta do aluno como extravagante e como um grande problema no ambiente escolar. A expressão "perturba demais", aliada à narrativa detalhada de cada ação da criança, corrobora a imagem de aluno cuja atividade é atípica e irregular. Ao mesmo tempo, a fala da educadora produz uma descrição na qual contrasta a ação de um aluno considerado portador do distúrbio e a atividade regular de um aluno sem problemas. Faz isso por meio da frase "nesse sistema numa cadeirinha olhando a professora". No final de seu discurso, é evidente a justificativa do distúrbio como algo que interfere nas relações que ocorrem na escola.

As professoras Tirza e Marta também produzem descrições em que a atipicidade dos traços individuais é ressaltada. Em suas falas, o emprego do advérbio de tempo "sempre" funciona para mostrar que não se trata de um estado momentâneo do aluno, mas de uma ação constante e persistente. Nesse sentido, as educadoras utilizam uma gama de termos e expressões para apresentar todo o evento como algo excepcional (Potter, 1998).

Diferentemente do discurso da professora Tirza, encontram-se algumas falas que não enfatizam apenas o excesso de atividade do aluno. Em alguns discursos é possível encontrar a descrição de condutas que não trazem a inquietação como algo permanente. Isso fica visível na fala da professora Amélia: "Olha, às vezes ele fica bem caladinho, não faz nada, não é? Mas às vezes é demais. Aí brinca e conversa, não faz tarefa... é uma coisa séria assim" (Amélia).

Observa-se a variabilidade discursiva em relação às ações do sujeito considerado hiperativo: produz-se não somente a imagem do sujeito permanentemente inquieto, mas também de alguém que pode ficar desligado, ausente, mesmo que seja por um pequeno espaço de tempo. Esse aspecto fica mais claro quando os professores se referem à distração, ou, como cita Mattos (2001), ao estado de estar no mundo da lua.

Durante a aula... ele é muito disperso. Você tenta chamar a atenção dele. Ele tá olhando sempre pra algum lugar, por isso que eu acho que a mente dele deve tá a mil, parada em algum lugar, menos ali dentro da sala de aula (Carla).

0 comportamento dessa criança. Como eu diria, não é? Vê bem... são super aéreas, prestam atenção em tudo menos nas atividades, certo. Sentam pouquíssimo, porque assim que sentam levantam. Não faz atividade nem de classe e nem de casa, porque acredito que, se na escola é assim, em casa é pior (Nilma). 
Rapaz, eu acho que eu tenho neste ano uma com transtorno de atenção. Ela tem uma falta de atenção enorme. Porque qualquer aviso que eu dou, se eu não anotar, ela não lembra. E ela é aquele tipo de criança assim... se você falar alguma coisa agora... conteúdo mesmo, falar alguma coisa agora, daqui a alguns minutos ela não lembra mais (Marília).

Na descrição da professora Carla, o estado do aluno "hiperativo" não aparece como algo permanente, pois, ao iniciar sua descrição pelo termo "durante”, que na frase construída funciona como uma preposição de tempo, ela indica que a dispersão do aluno ocorre no momento específico da aula. A partir daí, a educadora procura justificar a desatenção e a falta de interesse do aluno por meio de um argumento que enfatiza problemas neurológicos: "a mente dele deve tá a mil, parada em algum lugar". Ao realizar essa ação no discurso, a educadora mina qualquer contra-argumentação sobre outros fatores que pudessem ser os responsáveis pelo desinteresse do discente. Reforça a própria deficiência do aluno.

Nilma também constrói um relato no qual é enfatizado o alheamento do sujeito. Faz isso utilizando o prefixo "super" antes da palavra "aérea”, cuja função é enfatizar o alto nível de desatenção do aluno. Retoricamente, seu argumento é organizado para criar certo consenso sobre as ações do aluno em casa e na escola (Potter, 1998). O efeito desse tipo de organização discursiva é chegar à conclusão de que as dificuldades em realizar as atividades estão unicamente ligadas à patologia da criança. 0 juízo consensual aparece no final da fala da educadora, quando procura justificar o desempenho "pior" do aluno no ambiente extraescolar.

Quanto à narrativa da professora Marília, vê-se claramente que ela produz gradualmente o estado de doença do discente. Ela faz isso a partir da descrição detalhada de cada episódio de desatenção do aluno, com a finalidade de causar impressão de que a criança se comporta de uma forma doentia. Ao mesmo tempo, a professora contrasta sua própria ação com a do aluno, a fim de corroborar sua narrativa sobre a conduta desviante sobre "aquele tipo de criança".

Nota-se, nas falas das educadoras supracitadas, uma total ausência de outras opções para explicar a desatenção dos alunos. A possibilidade de tal desinteresse ser uma reação às longas horas dentro da sala de aula ou, mesmo, uma resposta a tarefas desinteressantes ou a aulas cansativas não aparece nessas falas.

Além disso, os discursos trazem como efeito a produção da imagem de um sujeito não adaptado ao modelo de escola ainda muito prevalecente em nossa sociedade, 
um modelo tão bem descrito na fala da professora Maria. Esse tipo de escola, bem como a relação entre os sujeitos nela inseridos, é problematizado por autores como Aquino (1996, 1998) e Passos (1996).

São instituições nas quais, em geral, prima-se pela homogeneização, pela disciplina, pela realização de tarefas e pela atenção. Dessa forma, quando as professoras constroem seus discursos, de forma a colocar o aluno em algumas das categorias supracitadas-categorias recusadas pelo modelo escolar predominante-, elas estão posicionando os alunos, implicitamente, como responsáveis por seus problemas escolares.

Retoricamente, as falas que descrevem os alunos, por meio de explicações que enfatizam a atividade acima da média ou a desatenção, têm a função de produzir uma versão da realidade na qual todas as deficiências escolares desses discentes têm origem neles próprios. Logo, o contexto social em que ocorrem as ações do sujeito, como, por exemplo, o espaço escolar, a prática pedagógica e o currículo, não é problematizado, ficando isento de qualquer responsabilidade em relação às dificuldades apresentadas por tais indivíduos.

\section{Conclusão}

Os resultados discutidos acima mostram a ausência de um significado unívoco para o termo TDAH. Observou-se, nas falas, o uso de expressões que remetem a um repertório estritamente médico e à linguagem cotidiana, para dar sentido ao distúrbio. Muitas definições são fundamentadas na concepção dos docentes sobre o que seja “um aluno normal”. Logo, é a partir das produções estabelecidas socialmente a respeito da "normalidade" que os professores elaboram suas descrições e os sentidos do TDAH.

O mesmo parâmetro é usado quando as professoras descrevem as características negativas do aluno hiperativo. Nesse caso, a ênfase recai sobre os comportamentos desviantes em relação às normas ou aos modelos instituídos historicamente $\mathrm{e}$ ainda prevalecentes na escola contemporânea. Esses modelos tendem a construir estereótipos dos alunos que apresentam atividade acima da média ou daqueles mais distraídos.

Na maioria dos discursos, evita-se problematizar questões mais amplas como, por exemplo, práticas pedagógicas, currículo, modelo escolar ou políticas educacionais. Ao contrário disso, há uma tendência em utilizar argumentos e teorias que enfatizam, implícita ou explicitamente, questões psicológicas e biológicas. Na verdade, a 
maioria das falas é construída de modo a individualizar o problema, por meio de uma espécie de discurso que evita críticas à escola e a seus atores.

A variabilidade encontrada nas falas das educadoras, possivelmente, é atravessada pelas contradições e pela controvérsia presentes em distintos discursos que circulam na sociedade, o que leva as docentes a adotarem diferentes posicionamentos a respeito do distúrbio e do que é aceitável socialmente.

O estudo permite concluir que a questão do TDAH e da relação da escola com os alunos classificados como hiperativos deve ser objeto de ampla reflexão na comunidade escolar e de ações que promovam a discussão sobre a inserção desses sujeitos no espaço educativo. Além disso, é importante ressaltar que essa discussão mais ampla não pode ter apenas um caráter prescritivo. É preciso também uma reflexão mais ampla dos educadores a respeito dos pressupostos ideológicos que regem suas práticas. 


\section{Referências bibliográficas}

American Psychiatric Association/APA (2002). DSM IV TR - Manual Diagnóstico e Estatístico de Transtornos Mentais (4a ed. revisada). Porto Alegre: Artes Médicas.

Aquino, J. G. (1996). A desordem na relação professor-aluno: indisciplina, moralidade e conhecimento. In J. G. Aquino (Org.), Indisciplina na escola: alternativas teóricas e práticas (9a ed., pp. 39-55). São Paulo: Summus.

Aquino, J. G. (1998, julho/dezembro). A indisciplina e a escola atual. Revista da Faculdade de Educação, 24(2), 181-204.

Aquino, J. G. (2001, julho/novembro). Alunos problema versus alunos diferentes: avesso e direito da escola democrática. Pro-Posições, 12(2-3), 91-108.

Benczik, E. B. P. (2002). Transtorno de déficit de atenção/hiperatividade: atualização diagnóstica e terapêutica: características, avaliação, diagnóstico e tratamento: um guia de orientação para profissionais. São Paulo: Casa do Psicólogo.

Benedetti, I., \& Cunha, S. U. (2008, dezembro). Escola, ética e cultura contemporânea: reflexões sobre a constituição do sujeito que não aprende. Psicologia da educação, 27, 141-155.

Billig, M. (2008). Argumentando e pensando: uma abordagem retórica à psicologia social. Petrópolis/RJ: Vozes.

Caliman, L. V (2009, janeiro/abril). A constituição sócio-médica do fato TDAH. Psicologia \& Sociedade, 21(1), 135-144.

Canguilhem, G. (1995). O normal e o patológico. (4a ed.). Rio de Janeiro: Forense Universitária.

Collares, C. A. L., \& Moysés, M. A. A. (1996). Preconceitos no cotidiano escolar: ensino e medicalização. São Paulo: Cortez / FE-FCM-UNICAMP.

Edwards, D. (2006). Discourse, cognition and social practices: The rich surface of language and social interaction. Discourse Studies, 8(1), 41-49.

Foucault, M. (2001). Os anormais. São Paulo: Martins Fontes.

Gill, R. (2002). Análise de discurso. In Bauer, M. W., \& Gaskell, G. (Ed.), Pesquisa qualitativa com texto, imagem e som: um manual prático. (pp. 244-269, 2a ed.). Petrópolis: Vozes.

Gomes, M. et al. (2007). Conhecimento sobre o transtorno do déficit de atenção/hiperatividade no Brasil. Jornal Brasileiro de Psiquiatria, 56(2), 94-101.

Graeff, R. L., \& Vaz, C. E. (2008). Avaliação e diagnóstico do transtorno de déficit de atenção e hiperatividade (TDAH). Psicologia USP, 19(3), 341-361.

Landskron, L. M. F., \& Sperb, T. M. (2008, junho). Narrativas de professoras sobre 0 TDAH: um estudo de caso coletivo. Psicologia Escolar e Educacional, 12(1), 153-167. 
Lang, A. B. S. G., Campos, M. C. S. S., \& Demartini, Z. B. F. (2001). História Oral e pesquisa sociológica: a experiência do CERU (29a ed.). São Paulo: Humanitas.

Legnani, V. N., \& Almeida, S. F. C. de. (2008). A construção diagnóstica de Transtorno de Déficit de Atenção/Hiperatividade: uma discussão crítica. Arquivos Brasileiros de Psicologia, 60(1), 02-13.

Mattos, P. (2001). No mundo da lua. São Paulo: Lemos Editorial.

Oliveira Filho, P. de (2011). A Psicologia Social Discursiva. In A. R. R. Torres et al. (Orgs.), Psicologia Social: temas e teorias (pp. 351-358). Brasília: Technopolitik.

Passos, L. F. (1996). A indisciplina e o cotidiano escolar: novas abordagens, novos significados. In J. G. Aquino (Org.), Indisciplina na escola: alternativas teóricas e práticas (pp.117-127, 9a ed.). São Paulo: Summus.

Patto, M. H. S. (2002). A produção do fracasso escolar: histórias de submissão e rebeldia. São Paulo: T. A. Queiroz.

Potter, J. (1998). La representación de la realidad: discurso retórica y construcción social. Barcelona: Paidós.

Potter, J., \& Wetherell, M. (1987). Discourse and Social Psychology: beyond attitudes and behaviour. London: Sage.

Rohde, L. A., \& Halpern, R. (2004, abril).Transtorno de déficit de atenção/hiperatividade: atualização. Jornal de Pediatria, 80(2), 61-70.

Silva, K. C. B. da (2010, janeiro/abril). Educação inclusiva: para todos ou para cada um? Alguns paradoxos (in)convenientes. Pro-Posições, 21(1), 163-178.

Spink, M. J., \& Medrado, B. (2000). Produção de sentido no cotidiano: uma abordagem teórico-metodológica para análise das práticas discursivas. In M. J. Spink (Org.), Práticas discursivas e produção de sentidos no cotidiano: aproximações teóricas e metodológicas (pp. 41- 61). São Paulo: Cortez.

Van Dijk, T. (2004). O giro discursivo. In L. Iñiguez (Coord.), Manual de análise do discurso em ciências sociais (pp.7-14). Petrópolis, RJ: Vozes.

Wetherell, M. (1998, July). Positioning and interpretative repertoires: Conversation analysis and poststructuralism in dialogue. Discourse and Society, 9(3), 387-412.

Wetherell, M., \& Potter, J. (1992). Mapping the language of racism: Discourse and the legitimation of exploitation. Hemel Hempstead: Harvester Wheatsheaf.

Submetido à avaliação em 11 de fevereiro de 2014; aceito para publicação em 3 de setembro de 2014. 